\title{
Drug Treatment in Non-Dialysed Chronic Renal Failure Patients in Senegal (West Africa)
}

\author{
Cisse $\mathrm{MM}^{1}$, Diawara $\mathrm{MS}^{1 *}$, Kane $\mathrm{Y}^{3}$, Fall $\mathrm{K}^{2}$, Lemrabott $\mathrm{AT}^{2}$, Faye $\mathrm{Ma}^{2}$, Diallo $\mathrm{P}^{2}$, Faye $\mathrm{MO}^{2}$, $\mathrm{Ka} \mathrm{F}^{2}, \mathrm{Niang}^{2}$ and Diouf $\mathrm{B}^{2}$ \\ ${ }^{1}$ Department of Nephrology, Regional Hospital of Thies, Senegal \\ ${ }^{2}$ Department of Nephrology, Teaching Hospital Dantec, Senegal \\ ${ }^{3}$ Department of Nephrology, Regional Hospital of Zinguinchor, Senegal
}

\begin{abstract}
Introduction: In Senegal the drug prescription in chronic renal failure patients (CRF) is not well appreciated. The objectives of this study were to analyze drug prescription in patients with non-dialysis CRF, the factors' progression for chronic renal disease (CKD) and occurrence of death related to drug prescription.
\end{abstract}

Patients and Methods: It was a retrospective, descriptive and analytical study carried out in the nephrology department of the LEDANTEC hospital in Dakar from January $1^{\text {st }}, 2015$ to December $31^{\text {st }}, 2015$. Were included any patient received in consultation or hospitalization with a CKD from Stage 3 and not dialyzed.

Results: The hospital prevalence was $6.06 \%$. The average age was $56.19 \pm 15.17$ years. The high blood pressure (HBP) was found in 138 patients $(81.66 \%)$ and 65 patients $(47.10 \%)$ did not have a precise treatment. Fortyseven patients $(28 \%)$ were diabetic and 9 badly followed-up. General signs such as paleness of mucosa $(57.14 \%)$ and lower limbs edema (52\%) were in the foreground while digestive $(7.69 \%)$ and neurological $(7.10 \%)$ signs were poorly represented. Therapeutically, a total of 65 drugs were prescribed and amlodipine was the most prescribed at $16.31 \%$. Forty-nine patients $(28.99 \%)$ had at least one drug contraindicated. The Acetylsalicylic acid was the most prescribed contraindicated drug 31 times or $52.54 \%$. One hundred and three patients, or $60.95 \%$, had at least one drug poorly adapted to renal function, and antihypertensives took over $90.91 \%$ of these inappropriate prescriptions. No maladaptation was related to the chronic renal disease development, but the contraindicated drugs had an influence on the death of the patients with a $p$ at 0.015 .

Conclusion: Our study shows that drugs contraindicated and poorly adapted to renal function are recurrently prescribed in non-dialyzed CRF. A use of the Prescription Guides and Kidney (GPR) recommendations before any prescription in the renal failure could improve the treatment in our structures.

Keywords: Drug prescription; Chronic renal failure; Dakar

\section{Introduction}

Chronic renal failure (CRF) is defined as the persistence for more than 3 months of renal impairment and/or a decrease of glomerular filtration rate $(\mathrm{GFR})<60 \mathrm{ml} / \mathrm{min} / 1.73 \mathrm{~m}^{2}$ of corporal surface [1,2]. The prevalence of moderate CKD is estimated at $6.5 \%$ in Switzerland, $7.7 \%$ in the United States and $8.1 \%$ in France [3-5]. According to a study conducted in Switzerland in 2014, only $45.1 \%$ [3] of patients had a drug treatment in conformity with the recommendations. However, studies around the world have concluded that there is a need to optimize the treatment of patients with CKD [6-11]. In Senegal, no study has been conducted on drug prescription in chronic renal failure patients. Based on this observation, we conducted this study to analyze drug prescriptions in patients with non-dialysis CKD in order to deduce the factors of progression of the CKD and the occurrence of deaths related to drug prescribing.

\section{Patients and Methods}

This is a retrospective, descriptive and analytical study from January 1, 2015 to December 31, 2015 conducted in the Nephrology Department of Aristide le Dantec Hospital. Patients admitted for consultation or hospitalization with chronic kidney disease from stage 3 and non-dialysed were included. All patients younger than 15 years old and patients with incomplete or unexploitable files were not included. For each patient, we collected epidemiological parameters, antecedents, clinico-paraclinical and etiological parameters using a survey form. Therapeutic measures and evolutionary parameters were also studied. Collected data has been entered and analyzed with Epi
Info software version 3.5.3. The qualitative variables were represented as percentages and the quantitative variables as an average more or less the standard deviation or with a minimum and a maximum the analytical study was done with the crosstabs. Chi- 2 or Fisher-test were used to compare frequencies with a threshold of significant alpha less than 0.05 .

\section{Results}

Out of 1025 patients admitted for consultation or hospitalized 169 had chronic renal disease from Stage 3 not dialyzed, resulting in a hospital prevalence of $6.06 \%$. The average age was $56.17 \pm 15.17$ years with extremes of 17 years, 90 years. The sex ratio was 0.88 . Alteration of renal function was the most common reason for consultation $(61.4 \%)$ followed by renal edema (8.88\%). Eleven patients (6.51\%) did not have a specified reason for consultation. High blood pressure (HBP) was noted in 138 patients (81.66\%) and 65 hypertensive patients (47.10\%) did not have a specific treatment. Forty-seven patients $(28 \%)$ were

*Corresponding author: Diawara MS, Department of Nephrology, Regional Hospital of Thies, Senegal, Tel: +221 77 6553438; E-mail: mamindiouga79@yahoo.fr

Received: October 10, 2019; Accepted: November 15, 2019; Published: November 22, 2019

Citation: Cisse MM, Diawara MS, Kane Y, Fall K, Lemrabott AT, et al. (2019) Drug Treatment in Non-Dialysed Chronic Renal Failure Patients in Senegal (West Africa). J Nephrol Ther 9: 339.

Copyright: ( 2019 Cisse MM, et al. This is an open-access article distributed under the terms of the Creative Commons Attribution License, which permits unrestricted use, distribution, and reproduction in any medium, provided the original author and source are credited. 
diabetic and 9 patients were poorly followed-up. In these diabetic patients, an oral anti diabetic prescription (OAD) was found in $29.79 \%$, insulin in $23.40 \%$ and $25.53 \%$ were given unspecified treatment. Herbal medicine was noted in 58 patients $(34.2 \%)$. Paleness of the mucosa (14.88\%) and renal edema (58\%) were the main general signs. The other general signs are shown in Table 1.

Physical signs were dominated by cardiac $50.9 \%$ and pulmonary $16.57 \%$ attack. The other signs are listed in Table 2. Of the 169 patients, $35.5 \%$ were in stage 5 of the CKD, $34.32 \%$ in stage 4 and $30.17 \%$ in stage 3 (Table 3).

The main biological abnormalities were anemia (83.11\%) and hyperkalemia (37.87\%). No patient had done the intact parathyroid hormone (PTH) test. The different biological abnormalities that represented comorbidities and complications are shown in Table 3.

Etiologically Nephroangiosclerosis (43.20\%) and diabetes (7.10\%) were the main etiologies of our study. Cases of nephropathy of undetermined cause were retained in 54 patients or $31.95 \%$.

Therapeutically, the etiological treatments used for hypertension and diabetes are shown in Figures 1 and 2.

A total of 65 drugs were prescribed and amlodipine was the most prescribed at $16.31 \%$ followed by furosemide at $10.88 \%$ and Atorvastatin at $7.96 \%$. Seventeen patients (10.06\%) had a drug prescription in conformity to recommendation, 49 patients $(28.99 \%)$ had at least one contraindicated drug, and 103 patients had at least one drug that was poorly adapted to kidney function (Table 3 ).

\begin{tabular}{|l|c|c|}
\hline General signs & Effectives & Percentages \\
\hline General state alteration & 25 & $14.88 \%$ \\
\hline Mucosa's paleness & 96 & $57.14 \%$ \\
\hline Extracellular dehydration & 12 & $7.14 \%$ \\
\hline Undernutrition & 8 & $4.76 \%$ \\
\hline Facial swelling & 27 & $16.07 \%$ \\
\hline Edema of the lower limbs & 58 & $34.52 \%$ \\
\hline
\end{tabular}

Table 1: Patients' Representation according General Signs.

\begin{tabular}{|c|c|c|c|}
\hline $\begin{array}{c}\text { Clinical } \\
\text { parameters }\end{array}$ & Clinical signs & Effectives & $\begin{array}{c}\text { Percentages } \\
(\%)\end{array}$ \\
\hline \multirow[t]{5}{*}{ Urogenital } & Hematuria & 4 & 2.37 \\
\hline & Pyuria & 6 & 3.55 \\
\hline & Maling burns & 4 & 2.37 \\
\hline & Lumbar contact & 1 & 0.59 \\
\hline & Prostatic hypertrophy & 4 & 2.37 \\
\hline \multirow[t]{6}{*}{ Cardiovascular } & Bradycardia & 4 & 2.37 \\
\hline & Tachycardia & 16 & 9.47 \\
\hline & Auscultatory arrhythmia & 4 & 2.37 \\
\hline & Right heart failure & 12 & 7.10 \\
\hline & Left heart failure & 22 & 13.02 \\
\hline & Breath & 28 & 16.57 \\
\hline \multirow[t]{3}{*}{ Breath } & Respiratory Pleural effusion & 6 & 3.55 \\
\hline & $\begin{array}{c}\text { Pulmonary condensation } \\
\text { syndrome }\end{array}$ & 18 & 10.65 \\
\hline & Other respiratory signs & 4 & 2.37 \\
\hline \multirow[t]{2}{*}{ Digestifs } & Uremic Breath & 8 & 4.73 \\
\hline & Sprayed tongue & 5 & 2.96 \\
\hline \multirow[t]{3}{*}{ Neurologiques } & Altered Conscience & 2 & 1.18 \\
\hline & Paresthesia & 8 & 4.73 \\
\hline & Deficit Engine & 2 & 1.18 \\
\hline
\end{tabular}

Table 2: Representation of patients by physical signs.

\begin{tabular}{|l|c|}
\hline Parameters & Effectives (Percentages) \\
\hline Average age & $56.17 \pm 15.17$ \\
\hline Sex-ratio & 0.88 \\
\hline High Blood pressure & $138(81.66 \%)$ \\
\hline Diabetes & $47(28 \%)$ \\
\hline Stage 3a CRF & $(11.83 \%)$ \\
\hline Stage 3 b CRF & $(18.34 \%)$ \\
\hline Stage 4 CRF & $(34.32 \%)$ \\
\hline Stage 5 CRF & $(35.5 \%)$ \\
\hline Anemia & $123(8311 \%)$ \\
\hline Hyponatremia & $33(23.91 \%)$ \\
\hline Hypernatremia & $6(4.35 \%)$ \\
\hline Hypokalemia & $10(5.92 \%)$ \\
\hline Hyperkalemia & $64(37.8 \%)$ \\
\hline Hypocalcemia & $29(17.16 \%)$ \\
\hline Hypercalcemia & $7(4.14 \%)$ \\
\hline Hypophosphoremia & $2(1.18 \%)$ \\
\hline Hyperphosphoremia & $46(27.22 \%)$ \\
\hline Dyslipidemia & $37(21.90 \%)$ \\
\hline Patients, drug treatment in conformity with & $17(10.06 \%)$ \\
\hline recommandations & $49(28.99 \%)$ \\
\hline Patients, contraindicated drugs & $103(60.95 \%)$ \\
\hline Poorly adapted drugs & \\
\hline
\end{tabular}

Table 3: Characteristics of the study population.

Contraindicated drugs (CI) based on stage and severity of CKD was prescribed 59 times in these 49 patients (28.99\%). Acetylsalicylic acid was the most prescribed contraindicated drug. It was administered 31 times or $52.54 \%$ of contraindicated prescriptions, followed by indapamide 7 times or $11.86 \%$. The prescribed IC drugs are shown in Figure 3.

One hundred and three patients, or $60.95 \%$, had at least one drug that was poorly adapted to kidney function. Poor dose adjustment to renal function was noted 121 times. The most frequent drugs maladapted to renal function were antihypertensives with $90.91 \%$ of prescriptions, followed by antibiotics with $5.79 \%$ of prescriptions (Figure 4).

Evolutionary, out of the 169 patients, 12 patients (7.10\%) evolved to stage 5 . Of these 12 patients, $3(1.78 \%)$ were initially in stage $3 \mathrm{~b}$ and $9(5.31 \%)$ in stage 4 of the CKD. One hundred patients (59.17\%) were not found, and three (1.78\%) patients died of unspecified cause. The number of maladapted drugs had no influence on the patient's death $(p=0.393)$ while the contraindicated drugs had an influence on the patient's death with a $\mathrm{p}$ at 0.015 .

\section{Discussion}

In our series the hospital prevalence of the CKD was $6.06 \%$ similar to the rate found in 2005 in Guinea which was 5.5\% [12]. Higher prevalences in Saint-Louis by Seck study of $10.8 \%$ [13] and in Nouakchott by Meyloud [14] of $17.22 \%$ were noted. In the United Kingdom this figure was $40 \%$ among those aged 65 and over [1]. The high prevalence in the industrialized countries is certainly due to the longer life expectancy in these areas and better survival of patients with CKD through integrated treatment. The low prevalence in our series compared to Saint Louis and Nouakchott, can be explained by the fact that the Nephrology Department of Dakar receives a larger number of patients (about 1025 patients per year against 555 in Saint Louis and 261 in Nouakchott).

The history of high blood pressure was noted in 138 patients or 
Citation: Cisse MM, Diawara MS, Kane Y, Fall K, Lemrabott AT, et al. (2019) Drug Treatment in Non-Dialysed Chronic Renal Failure Patients in Senegal (West Africa). J Nephrol Ther 9: 339.

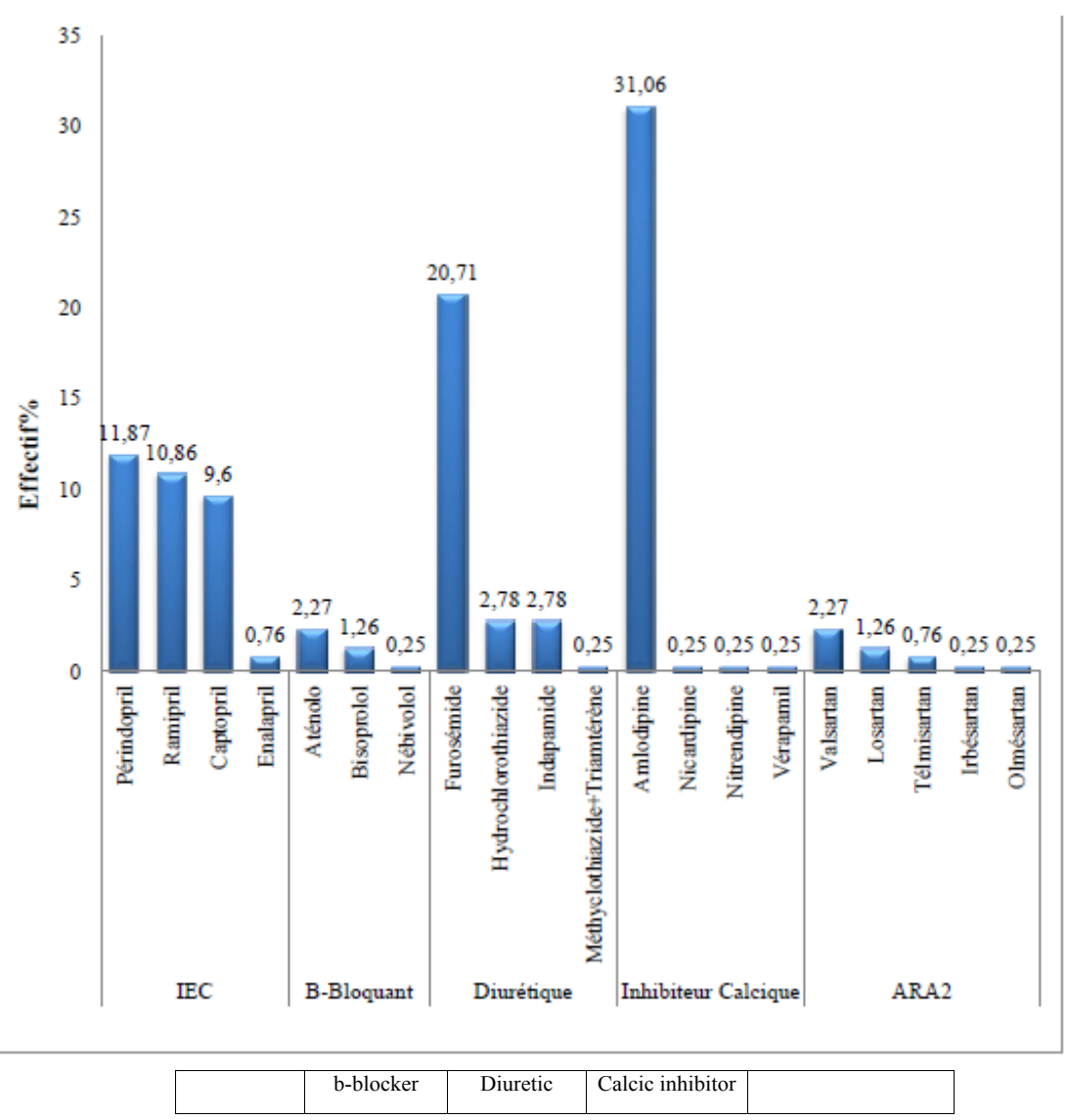

Figure 1: Representation of patients according to the anti-HBP molecules received.

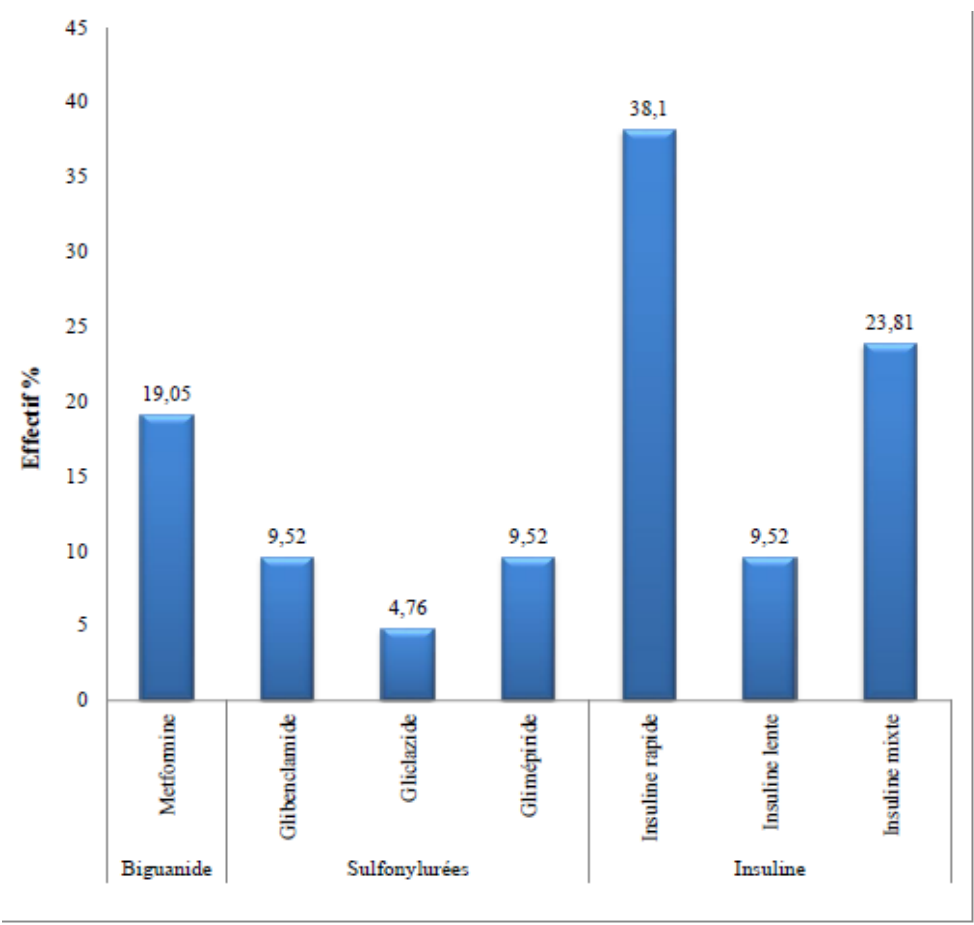

Figure 2: Patient representation by antidiabetic class used. 
Citation: Cisse MM, Diawara MS, Kane Y, Fall K, Lemrabott AT, et al. (2019) Drug Treatment in Non-Dialysed Chronic Renal Failure Patients in Senegal (West Africa). J Nephrol Ther 9: 339.

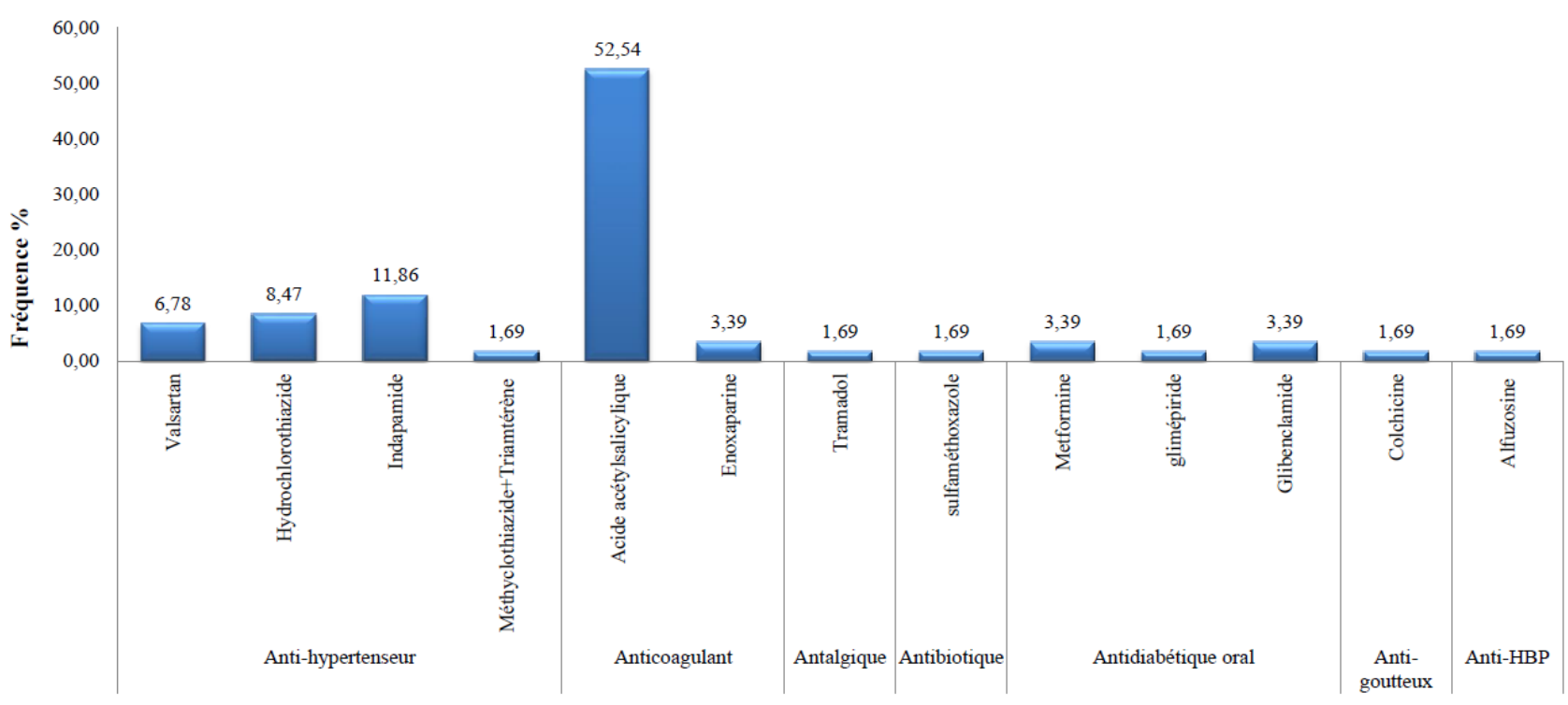

Figure 3: Representation of frequency of prescription of drugs against indicated

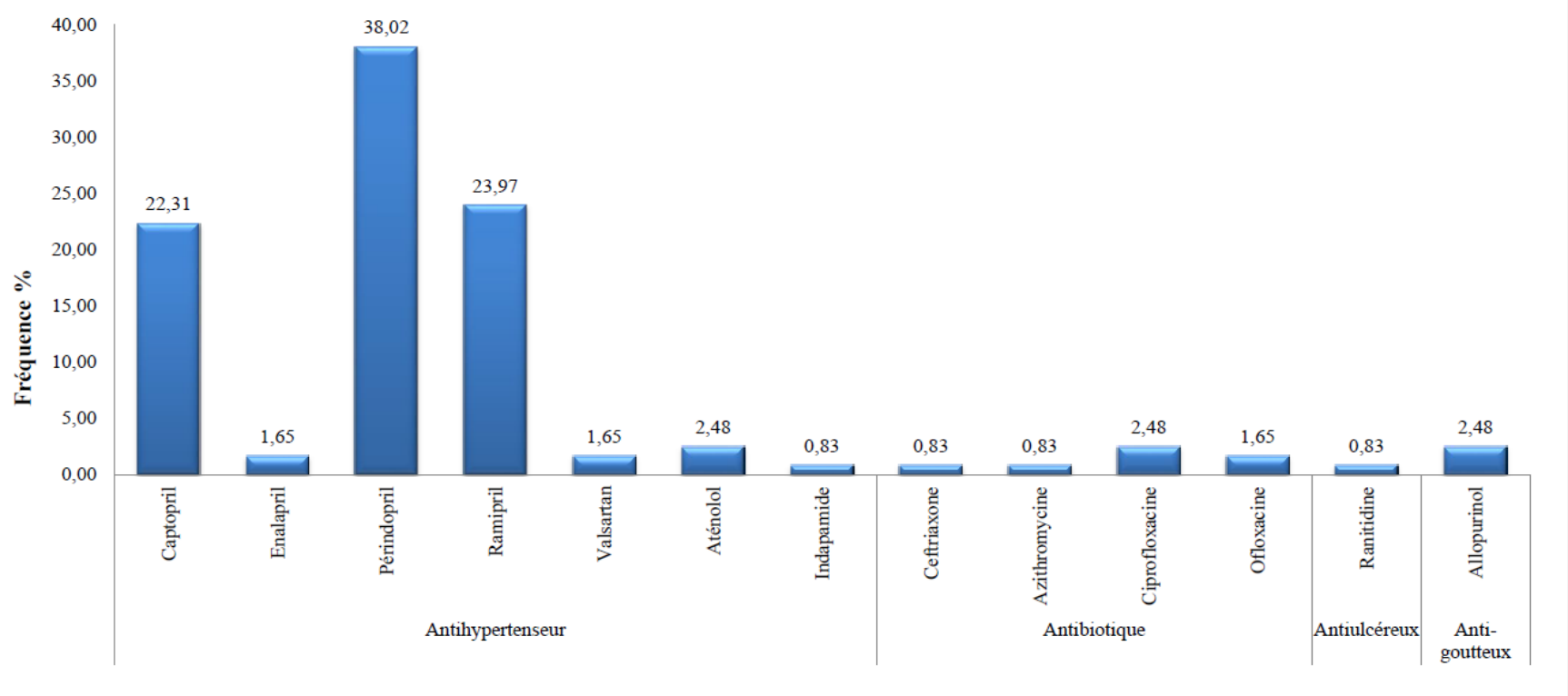

Figure 4: Representation of the prescription frequency of drugs that are poorly adapted to renal function.

$81.66 \%$. These results were similar to those in St. Louis $83 \%$ of patients. Other African studies confirmed our data. Type 2 diabetes was the second antecedent found in our $27.81 \%$ series. A lower prevalence of $18 \%$ was noted at ST-LOUIS [13]. The notion of taking herbal medicine was noted in 58 patients or $34.32 \%$. In Western studies, this antecedent was not described. The geographical and financial inaccessibility to specialized medical structures as well as the socio-cultural beliefs present in our regions are factors that explain this important phytotherapy.
Therapeutically, $16.57 \%$ had benefited from a CRF diet, $33.73 \%$ from a low sodium diet, $11.24 \%$ from a water restriction, $2.37 \%$ from a hypokalaemic diet and $0.59 \%$ from a hypophosphoremic diet. Sixtyfour patients, $37.87 \%$, had hypercalcemia and 30 , or $17.75 \%$ had sodium polystyrene sulfonate. Hyperphosphatemia was found in 46 patients (27.22\%), and none of them were given Sévélamer hydrochloride. Hyperphosphatemia was one of the less supported comorbidities in patients. This may be a factor in the progression of chronic kidney 
Citation: Cisse MM, Diawara MS, Kane Y, Fall K, Lemrabott AT, et al. (2019) Drug Treatment in Non-Dialysed Chronic Renal Failure Patients in Senegal (West Africa). J Nephrol Ther 9: 339.

disease, but no link was established between the progression of chronic kidney disease and hyperphosphoremia $(\mathrm{p}=0.208)$.

Out of the 103 patients who had anemia alone, 77 patients $(45.56 \%)$ received treatment, $29.59 \%$ under oral iron, $8.88 \%$ under iron injection, 4.14\% transfused and $2.96 \%$ under Erythropoietin treatment. The low percentage of erythropoietin treatment is due to the inaccessibility of the product, because the cost remains very high for patients who for the most part are without medical coverage. Thus, anemia was the leass treated comorbid/complication, with over one-third of untreated anaemic patients. This result was similar to that of the Swiss study [3] with anemia that was only treated in $25 \%$ of patients.

The HBP treatment for hypertension was mostly represented by calcium channel blockers (31.81\%), followed by angiotensinconverting enzyme inhibitors (33.09\%), diuretics (26.52\%), ARBs $(4,79 \%)$ and then B-blockers (3.58\%) unlike in St. Louis, with SECK [13] where diuretics (55\%) were the most prescribed.

In our series, we had 47 patients (28\%) with diabetes. And among these diabetics, only $21(12.43 \%)$ were on antidiabetic. In fact, type II diabetics tend to normalize their advanced CRD glycaemia, especially at stage $\mathrm{V}$, because of the absence of elimination of insulin by the kidney. In the study population, $35.3 \%$ were at stage $\mathrm{V}$. This could explain this low treatment of diabetics.

A total of 65 drugs were prescribed in the patients in our study, while 149 drugs were listed in the prescriptions of the Swiss study [3]. The drugs were prescribed 754 times, against 627 in Switzerland. Seventeen patients, or $10.06 \%$, had a drug prescription as recommended. This result is lower than that of Reutemann in Switzerland which was $45.1 \%$ (3). This unconformity between our results could be explained by the difference between inclusion criterion and optimal treatment judgment.

One hundred and three patients, or $60.95 \%$, had at least one drug that was maladapted to renal function, whereas in Switzerland, dosages not adapted to renal function were found in $29.6 \%$ of patients [3]. Poor dose adjustment to renal function was noted at $16.04 \%$ of prescriptions compared to $3.7 \%$ in the Swiss study [3]. Forty-nine patients, or $28.99 \%$, had gone with at least one contraindicated drug, compared to 9.9\% in Switzerland. This difference noted between our study and that of Switzerland could be explained by an easier accessibility (financial and availability) of medicines indicated in developed countries.

\section{Conclusion}

In Senegal, chronic kidney disease is a major public health problem because of the factors' occurrence often common to other pathologies. Our study shows that contraindicated drugs and that maladapted to renal function are recurrently prescribed in non-dialyzed CKD. A use of the Prescription Guides and Kidney (GPR) recommendations before any prescription in the renal failure could improve the care in our structures.

\section{References}

1. Aimun KA, Siobhan HM B, Abdelhafiz AH (2010) Chronic Kidney Disease in Older People; Disease or Dilemma? saudi J Kidney Dis Transpl 21: 835-841.

2. ANAES (2014) Diagnosis of chronic renal failure in adults.

3. Reutemann B, Beney J, Gunten VV, Roulet $L$ (2015) Drug treatment in patients with chronic kidney disease in the acute care ward of a Swiss regional hospital Nephrology \& Therapeutics.

4. Nahas ME, Kawar BS, Kossi ME (2012) Epidemiology, etiology, pathophysiology and staging of chronic kidney diseases. Nephrology Secrets, pp: 131-141.

5. Weiss M (1998) Renal effects of renin-angiotensin system blockade: AT angiotensin II receptor antagonists versus ACE inhibitors in hypertensive renal failure. Pharmacy thesis: Strasbourg.

6. Stevens PE, O'Donoghue DJ, deLusignan S, Vlymen JV, Klebe B, et al. (2007) Chronic kidney disease management in the UK: NEOERICA project results. Kidney Int 72: 92-99.

7. Nissenson AR, Collins AJ, Hurley J, Petersen H, Pereira BJG, et al. (2001) Opportunities for improving the care of patients with chronic renal insufficiency: Current practice patterns. J Am Soc Nephrol, 12: 1713-1720.

8. Abdel-Kader K, Fischer GS, Johnston JR, Gu C, Moore CG, et al. (2011) Characterizing pre-dialysis care in eGFR reporting: a cohort study. BMC Nephrology 12: 12

9. Quartarolo JJ, Thoelke M, Schafers SJ (2007) Reporting of estimated glomerular filtration rate: effect on medical recognition of chronic kidney disease and prescribing practices for elderly hospitalized patients. J Hosp Med 2: 74-78.

10. Bailie GR, Eisele G, Liu L, Roys E, Kiser M, et al. (2005) Patterns of medication in the RRI-CKD study: focus on medications with cardiovascular effects. Nephrol Dial Transplant 20: 1100-1115.

11. Belaiche S, Romanet T, Bell R, Calop J, Allenet B, et al. (2010) Pharmaceutica care in chronic kidney disease: experience at Grenoble University Hospital from 2006 to 2010 . J Nephrol 25: 558-565

12. Kaba L, Lanmh, Moudachirou M (2007) Prevalence of renal failure in patients aged 60 years and over hospitalized by the emergency department. Evolution at nine-year intervals (1997-2005). Nephrol Ther 3: 340-345.

13. Seck SM, Diallo IM, Diagne SIL (2013) Epidemiological Patterns of Chronic Kidney Disease in Black African Elders: A Retrospective Study in West Africa. Saudi J Kidney Dis Transpl 24: 1068-1072.

14. Teyeb MO (2012) Chronic renal failure in a hospital in Nouakchott: paraclinical and etiological clinical and therapeutic aspects. Thesis Med. 